\title{
Helium and Hydrogen Gas Accumulations
}

\author{
CHRIS J BALLENTINE ${ }^{1}$, BARBARA SHERWOOD \\ LOLLAR $^{2}$ AND JON GLUYAS ${ }^{3}$ \\ ${ }^{1}$ University of Oxford \\ ${ }^{2}$ University of Toronto \\ ${ }^{3}$ Durham University \\ Presenting Author: chris.ballentine@earth.ox.ac.uk
}

The principles behind helium and hydrogen generation in the crust are well understood. The processes controlling their transport and accumulation in the near surface are less clear. Helium production is a result of the radioactive decay of uranium and thorium. Hydrogen is generated by both water radiolysis, linking it to helium production, and reactions between mafic minerals and water [e.g. 1]. The availability of water for radiolysis, and water-rock reaction, provide variables in quantifying regional hydrogen production rates. Hydrogen can be biologically and chemically consumed.

The production rate of both gases to produce commercially useful amounts can be on $100 \mathrm{Ma}$ to $1 \mathrm{Ga}$ timescales and dispersed through large volumes of the crust. In quiescent continental crust, diffusion brings these gases to the near surface $[2,3]$. Within overlying sedimentary basins, the helium flux can overprint any local production and accumulate in the groundwater [3] $\mathrm{CH}_{4}$ or $\mathrm{CO}_{2}$ gas sources are the most common causes of gas phase formation in the nascent groundwater. This can generate Helium-rich gas fields when the ratio of mix-gas to dissolved helium is low [e.g. 4]. Helium-associated hydrogen is rarely found in such gas fields and might be assumed to be consumed during transport or while in the groundwater prior to gas phase formation.

Thermal perturbation of ancient continental crust through rifting (c.f. Tanzania [3]), plume impingement (c.f. Yellowstone [6]) or smaller-scale local events can result in a helium (and helium-associated hydrogen) flux greater than the diffusion controlled rate. This flux likely has a significant advective component with flow controlled by major structural features. Accumulation of significant gas volumes depends on the availability of trapping structures and, critically, gas phase formation. In the case of hydrogen, surface seeps containing both helium and hydrogen may reduce the possibility that biological or chemical removal of the deep hydrogen has been significant in local trapping structures.

[1] Sherwood Lollar et al., Nature 2014

[2] Neretnieks (2013) Hydrogeology Journal 21, 1701-1716

[3] Torgersen (2010) https://doi.org/10.1029/2009GC002930

[4] Ballentine and Sherwood Lollar (2002) Geochim. Cosmochim. Acta. 66, 2483-2497

[5] Danabalan (2017) Unpublished PhD thesis, University of Durham

[6] Lowenstern et al.,

https://doi.org/10.1038/nature12992 